\title{
Shift From Deciduous to Coniferous Forest in Southern Scandinavia Driven by Climate Change and Land-Use Interactions
}

Large-scale changes in land-cover can have significant feed-backs to climate and we have documented a rapid shift from deciduous to primarily coniferous forest types in southern Scandinavia (Fig. 1). This shift began about 1500 years ago but analysis of rates of vegetational change, based on a suite of pollen analyses from small forest hollows in southern Sweden, showed that the most rapid changes occurred during the last 150 years (Lindbladh et al., 2000).

We exploited the versatile nature of paleoecological data in order to work at both regional and stand scales within the boreo-nemoral zone of southern Sweden. Our major aim was to place recent vegetational change, sensed at two spatial scales, into a longer time perspective, breaking free from the normal constraints of neo-ecology. We had two unique paleoecological data sets at our disposal. Sixteen forest hollow sites yielded rather accurate but spatially restricted reconstructions of forest vegetation within maximum radii of a few hundred metres (Jackson and Kearsley, 1998). The regional data set covered a far larger proportion of the landscape but its value was limited by the inherent bias incurred when reconstructing vegetation using pollen that has dispersed long distances. The combination of these two data sets permitted more precise reconstructions of former tree distributions.

A detrended correspondence analysis (DCA) of the calibrated pollen data from the individual forest stands for 1250 BC, AD 500 and present, portrayed the similarities and differences between the sixteen individual stand histories. All stands moved away from the rich deciduous forest represented by Alnus, Corylus, Quercus and Tilia with some Fraxinus and Ulmus. The commonest successional pathway was via Betula and Carpinus to forest comprised of Picea and Pinus, although two stands became dominated by Fagus. The role of Betula as a prominent species in forests undergoing transition from deciduous to coniferous was emphasised in the DCA and many stands were at this intermediate stage at AD 500. The same tendency was observed at the regional scale especially in the central region of the study area. Only one stand showed a distinctly divergent pattern. Thus, although unique successional pathways can occur, the general pattern in southern Sweden during the last 3250 years has been along the pathways that lead to Picea- and to a lesser extent to Fagus-dominated stands.

A strong correlation between a decline in the percentages of pollen from deciduous trees and an increase in cereal pollen suggested that much of the vegetational development during the last 1000 years in southern Sweden could be largely explained by human impact through forest clearance and grazing management (Bradshaw and Mitchell, 1999). Direct climatic influence was of greater importance earlier in the Holocene (Cheddadi et al., 1997). Jacobson et al. (1987) carried out a rate of change analysis on regional pollen data from eastern North America and they argued for a continu-

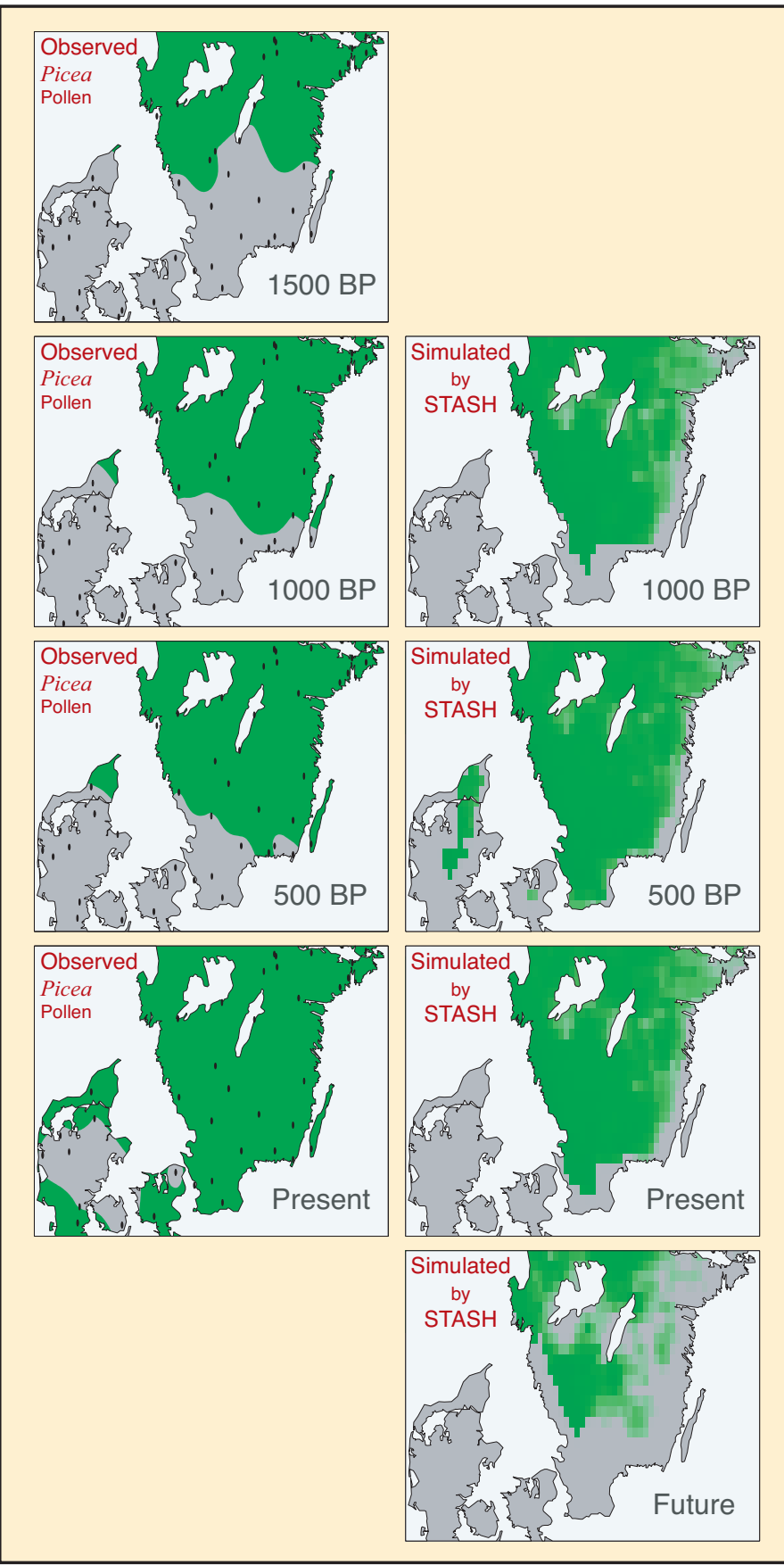

Figure 2: Observed and simulated Picea distributions during the last 1500 years. The observed distributions are reconstructed from fossil pollen data. The simulated distributions are generated by the bioclimatic model STASH. The predicted future distribution assumes an atmospheric $\mathrm{CO}_{2}$ composition twice that of present. ous underlying climatic control of the rate of vegetation change. The global climatic fluctuations during the last 1500 years that in Europe have included the Mediaeval Warm Period (MWP) and the Little Ice Age (LIA) have been regarded as among the most extreme experienced during the entire Holocene (Keigwin 1996), and a reaction of forest vegetation to these changes might be anticipated.
In order to explore this possibility we compared the paleoecologically mapped distributional changes of Picea abies in southern Scandinavia during the last 1500 years with modelled limits generated by the bioclimatic model STASH (Sykes et al., 1996; Bradshaw et al., in press). STASH predicts the equilibrium range boundaries associated with particular climates. It takes into account 
the response of species to winter cold, growing season warmth and soil moisture. The climate database used to run STASH comprised paleotemperature anomalies reconstructed from Fennoscandian tree-rings (Briffa et al., 1992) and paleoprecipitation anomalies obtained from the semi-quantitative historical reconstruction by Lamb (1967) covering the last 1000 years. The application of northern data to southern Scandinavia is supported by the observation that major northern temperature anomalies are duplicated in shorter datasets from further south (KalelaBrundin, 1999).

The comparisons of observed and modelled range limits for Picea in southern Scandinavia strongly suggested that the species distribution has tracked climate change during the last 1000 years, with only a small lag owing to the limits imposed by seed dispersal (Woods and Davis, 1989)(Fig. 2). The rate of change of the European Picea distributional limits has been rather slow during the last 1000 years compared to earlier in the Holocene, when very rapid rates of population expansion were recorded (Huntley and Birks, 1983). During the last 1000 years, the modelled, climatically imposed, potential range limits have been relatively stable, with some oscillations back and forth during the MWA and LIA. The realised range limit of Picea has approached the potential range limit and overshot during the last few centuries as a result of planting and establishment during climatically favourable years. Future predictions suggest that the range will retreat northwards, and outlying populations will be out of equilibrium with climate and under threat.

We conclude that the shift from deciduous to coniferous forest that we observed in southern Scandinavia was driven by anthropogenic land-use changes acting in conjunction with climate-driven shifts in distributional limits of a forest dominant - Picea abies. The climatic component is largely concealed by the anthropogenic, which comprises changes in grazing management and agricultural practices. Future research carried out as part of HITE will investigate the reversibility of this change and its possible feeedbacks to the global climate system.

\section{Richard Bradshaw}

Department of Environmental History and Climate Change, Geological Survey of Denmark and Greenland, Copenhagen, Denmark

rhwb@geus.dk

\section{MatTs LiNDBLADH}

Southern Swedish Forest Research Centre, Alnarp, Sweden

matts.lindbladh@ess.slu.se

\section{BJörn H. HoLmQvist}

Department of Quaternary Geology, Lund University, Sweden

bjorn_h.holmqvist@geol.lu.se

\section{Sharon Cowling}

National Center for Ecological Analysis and Synthesis (NCEAS), University of California, USA

cowling@nceas.ucsb.edu

For full references please consult www.pagesigbp.org/products/newsletters/ref2003.html

\section{Long Term Land-Cover Changes on Regional to Global Scales Inferred From Fossil Pollen - How to Meet the Challenges of Climate Research?}

Two major foci of global-change research are climate modelling and the use of paleoclimate reconstructions to test model outputs. In this respect, the effects of climate change on land-cover and the feed-back effects of land-cover change on climate belong to the numerous processes that we need to understand more fully over short and long time-scales.

A wealth of pollen data is presently available at more or less high-resolution over short to long time-scales, which represent an enormous potential for reconstructions of past land-cover at different temporal and spatial scales. However, setting up the approach and establishing the tools for translating pollen data into quantitative land-cover units are not an easy task.

\section{Earlier Aftempts to Quantify Landscape Openness in Europe}

Within the frame of the European Science Foundation "Climate and Man" programme (1985-1995, leader: B. Frenzel), a major focus was the assessment of land-cover changes in terms of deforestation/afforestation in Europe during the last 6000 calendar years and their possible role in climate change (e.g. albedo effects). Archeological and palynological data were brought together for a series of time windows in order to get an estimate of the extent of deforestation or afforestation (e.g. Frenzel, 1992), especially during the Roman Iron Age (c. AD 200) and the time of migrating German tribes (c. AD 600). In this reconstruction, maps of non-arboreal pollen (NAP) percentages for more than 200 selected sites were drawn for the two time slices. These maps were then interpreted assuming that changes in NAP percentages could be compared directly between sites and interpreted in terms of differences in landscape openness between sites and through time.

The results provided a clearer qualitative picture of the history of landscape openness in Europe. Periods of extensive deforestation are recorded in many areas already during the Bronze Age (from c. 3500-3000 calendar years), when the landscape may have been as open or even more open than today (e.g. in Britain, Ireland, Denmark and southern Sweden). However, the first period of major deforestation in Europe as a whole occurs during the Late Iron Age (from c. AD 500-0). In most areas, landscape openness increased further through the Middle Ages. Modern Times are characterised by contrasting developments in different parts of Europe. Some areas were simply abandoned, or the management changed from an agricultural to a sylvicultural one, both resulting in afforestation; in other areas deforestation continued.

\section{Case Study in Southern Sweden}

In southern Sweden, since 1989, a series of research projects have been devoted to the study of pollen/land-use relationships, with the purpose of improving pollen-analysis as a basis for reconstructing past cultural landscapes. A database of over 125 pollen assemblages (from moss polsters) and related vegetation and soil properties from non-fer- 